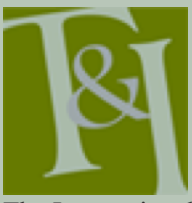

The International Journal for Translation \& Interpreting Research trans-int.org

\title{
Towards understanding interpreter trainees' (de)motivation: An exploratory study
}

\author{
Zhiwei $W u$ \\ Guangdong University of Foreign Studies \\ patrickwzw@163.com
}

DOI: 10.12807/ti.108202.2016.a02

\begin{abstract}
This paper reports on an exploratory study on profiling interpreter trainees' (de)motivation in a Chinese context. Reflective essays were collected from 40 postgraduate trainees, and questionnaires were administered to 120 undergraduate and postgraduate trainees. Based on the data collected, this paper examines the interrelation among the Criterion Factors (Motivation and Demotivation), the Internal Factors (Ideal Self, Instrumentality and Avoidance), and the External Factors (Teaching Methods, Perceived Supports and Perceived Competence). The study shows that (1) although generally high in motivation, interpreter trainees are susceptible to demotivation; (2) trainees' Ideal Self (future self-guide) is a better motivator than Instrumentality and Avoidance; (3) factors leading to trainee demotivation could be categorized into four groups: self-, peer-, teacher-, and institute-attributed, and Teacher Factor is the most frequently cited demotivating factor by trainees. Informed by these findings, the paper proposes an expanded research agenda on motivation in interpreting studies and highlights two new measures to encourage and sustain trainee motivation.
\end{abstract}

Keywords: motivation, demotivation, interpreter training, pedagogy

\section{Introduction}

The success of foreign language learning is largely contingent upon the cognitive and affective variables of language learners (Gardner \& MacIntyre, 1992, 1993). Among these variables, aptitude and motivation are highlighted by researchers as "the most consistent predictors of second language learning success" (Dörnyei \& Skehan, 2003, p. 589). The same principle could be applied to interpreter trainees, particularly those who bear the dual goals of attaining linguistic proficiency and interpreting competence. Motivation is an important factor in interpreting training, because it requires regular and sustained practice. For example, the very first advice Andrew Gillies gives to interpreter trainees is to "[p]ractise often" $(2013$, p. 11$)$; he also elaborates that "[f]ive days per week is a reasonable timetable" (ibid). Without a high level of motivation, it would be difficult for trainees to commit themselves to practice five days a week for at least one whole year (assuming that most MA interpreting programmes last for one year).

However, interpreter trainees are not machines into which teachers just feed materials and let the trainees/machines process them and produce something (Ellis, 2001, p.73). Learners, as human beings, experience changes in beliefs, attitudes, motivation and many other cognitive and affective attributes (see Larsen-Freeman, 2001). As such, it is important to understand how learners make sense of their learning environment, because "it is the learner's perceptions of external factors (rather than external factors in themselves) that mediate motivational growth within the self" (Ushioda, 
2014). The existing literature, however, seems to focus more on the cognitive aspects of interpreters (or interpreter trainees), without giving due attention to trainees' motivation (see Section 2 for a deeper discussion on this point).

To address this discrepancy, this paper reports on an exploratory study on profiling interpreter trainees' motivation and demotivation. The research topic was based on and inspired by a recent survey among 90 students in an MAlevel interpreting programme $(\mathrm{Wu}, 2015)$. It was found that only $40 \%$ of interpreter trainees had managed to keep up with their "deliberate practice" (Ericsson, 2000) over a year-long programme (Wu, 2015). Considering that all these students were self-selected, it could be argued that up to $60 \%$ of interpreter trainees were demotivated along the way. As an instructor/researcher, the author was surprised by the percentage of demotivated trainees, and wanted to understand the causes. The literature shows that the aforementioned case is not isolated. Interpreter trainees' motivation was also found to be declining in the postgraduate programme in the Newcastle University (Fan, 2012). Therefore, the author believes that the current research will shed light on the demotivation issues in interpreter training, where trainees are self-selected but might lose impetus during the training process.

\section{Motivation in interpreter training}

Research into motivation in the context of interpreter training mainly falls into three strands: a) the validity of motivation as a predictive factor in aptitude tests; b) the reasons why students choose to pursue interpreter training; c) the role of motivation in the interpreting pedagogy.

Amid the recent research interests in validating potential factors to predict interpreting students' success or 'teachability', motivation is usually considered and examined as one variable of the individual differences (IDs). For instance, Timarová and Salaets (2011) investigated the learning styles, motivation and cognitive flexibility among interpreting students and undergraduate students. They found that students who self-select for interpreting are cognitively more flexible, more achievement-driven and suffer less from stress. Shaw (2011) compared the cognitive and motivational difference across four groups, namely, high- and low-level spoken language (SP) and signed language (SL) interpreting students. A statistical difference was found between SP and SL students in terms of concentration and internality. High-level and low-level students were found to be statistically different in their concentration and eagerness to learn. Similarly, Rosiers, Eyckmans, and Bauwens (2011) compared the individual difference variables among 23 translation students and 13 interpreting students in a Belgian undergraduate programme. They found that translation students were prone to high levels of language anxiety, but no statistical difference was found in their integrative motivation or self-perceived linguistic competence. They also found that no significant correlation was attested between ID variables and the students' interpreting performance. Motivation, according to their findings, was not found to be correlated with language anxiety and self-perceived communication competence. On a different but related theme, Bontempo and Napier (2011) studied the potential individual personality traits as predictors of competence perceived by 110 accredited sign language interpreters in Australia. By means of questionnaires, they found that self-perceived interpreter competence was positively related to self-efficacy and negatively related to negative affectivity, while perceived interpreter competence was not significantly related to goal orientation (i.e. motivation). 
Another strand of motivation research in the context of interpreter education aims to unearth students' goal/orientation when choosing to learn interpreting. Yan, Pan, and Wang (2010), after surveying 45 interpreting learners in Hong Kong, identified five main reasons for learning interpreting namely, to improve their English, to improve their Chinese, to improve both languages, to be an interpreter, and to master the interpreting skills required for job seeking. They also found that nearly half of the students reported 'jobseeking' as their goal for learning interpreting.

Research into the role of motivation in teaching interpreting is somewhat scant. Two exceptions were found in the studies by Angelelli (2006) and Fan (2012). Angelelli placed emphasis on the cognitive factors of interpreting learners, which subsumed intrinsic motivation. She pointed out that "meaningful opportunities of contextualized practices and observation in a specific setting [...] followed by structured reflection in the classroom" could enhance students' intrinsic motivation (2006, p. 33-34). Fan, after surveying 30 stage- 1 and 11 stage- 2 students, found that students' intrinsic motivation showed no statistical difference, but the extrinsic motivation of stage-1 students declined and the amotivation of stage-2 students increased across three different time points (2012, p. 107, p. 112). The study also showed that "motivational types together added significantly to the prediction of CI [consecutive interpreting] performance", but not simultaneous interpreting performance (2012, p. 191).

In summary, these scholarly inquiries mainly tackle the issues of motivation when students are about to embark on the journey of interpreter training. Less attention has been given to motivational behaviours and student perception of demotivating factors during the journey. As mentioned earlier, aptitude and motivation are the two most stable factors in predicting students' performance in second-language acquisition. Therefore, motivation could serve as an important factor influencing students' beliefs, goals and involvement in the process of interpreter training. In addition, the extant research mainly focuses on why students choose to learn interpreting, while leaving the demotivation aspect unexamined. This echoes the observation made by Dörnyei and Ushioda (2011, p. 142) that "despite the widespread prevalence of language-learning failure, L2 demotivation remains a rather under-researched area". It could be argued that interpreter trainee demotivation is also under-researched and under-represented in the literature. Therefore, this exploratory study hopes to throw light on the (de)motivation issues in interpreter training, by analyzing trainees' perceptions of the (de)motivators in that training.

\section{Key terms defined}

In educational psychology, motivation is defined as "the process whereby goal-directed activity is instigated and sustained" (Schunk, Meece \& Pintrich, 2013 , p. 4). This definition suggests that motivation is usually inferred from people's behaviours, such as "choice of tasks, effort, persistence and verbalization" (ibid). This paper follows the tripartite-construct of motivation - i.e. why, how hard and how long trainees are willing to commit themselves to interpreter training.

In the seminal work by Gorham and Christophel (1992), 'demotivation' was defined as "lack of motivation", and 'demotivating factors' as those "decreasing students' motivation". To clarify the nuanced difference between lack of motivation and decreasing motivation, Dörnyei and Ushioda (2011, p.139) separate the competing notions of 'no motivation' (amotivation) and 
'decreasing motivation' (demotivation). To be consistent with the definition of motivation, demotivation in this study is operationalized as follows: a) trainees are reluctant to engage in interpreter training activities (choice); b) trainees find it more difficult to persist in interpreter training (persistence); c) trainees are less willing to invest effort in interpreter training (effort).

To understand the dynamics of (de)motivation in interpreter training, the internal and external factors affecting interpreter trainees are examined. Internal Factors denote those that are inherent in interpreter trainees, while the External Factors are those outside of the direct control of trainees. The selection of internal factors was guided by the findings in educational psychology and L2 motivation research, and three were identified: Ideal Self, Instrumentality, and Avoidance. The selection process was also informed by the definition of motivation: Ideal Self, Instrumentality and Avoidance are considered either as goals or as the antecedents of the goal-directed motivational behaviours. However, unlike the 'ideal self / ought-to self' distinction proposed by Dörnyei (2009), the paper treats Instrumentality and Avoidance (both of which are subsumed in Dörnyei's ought-to L2 self) as two separate factors, because studies have shown that the ought-to L2 self could not be identified as distinct from instrumental orientation (Csizér \& Kormos, 2009; Kormos \& Csizér, 2008). The differences between the three Internal Factors are twofold: a) Ideal Self is more future-oriented and more selfintegrated; b) Instrumentality and Avoidance are both external motivators, but the former is promotion-oriented and the latter is prevention-oriented (Higgins, 1987, 1998). Table 1 provides the detailed definitions and literature sources of these constructs in the context of interpreter training. The External Factors, on the other hand, all emerged from trainees' written responses, the details of which will be explained in section 5.1.

Table 1. Definitions and sources of three internal constructs

\begin{tabular}{lll}
\hline $\begin{array}{l}\text { Internal } \\
\text { factors }\end{array}$ & $\begin{array}{l}\text { Definitions adapted to the context of } \\
\text { interpreter training }\end{array}$ & Literature sources \\
\hline Ideal Self & $\begin{array}{l}\text { the representation of the attributes that } \\
\text { one desires to possess as an interpreter }\end{array}$ & $\begin{array}{l}\text { Angelelli } \quad(2006) ; \quad \text { Dörnyei } \\
(2009) ; \text { Higgins (1987) }\end{array}$ \\
Instrumentality & $\begin{array}{l}\text { the perceived utilitarian benefits of } \\
\text { interpreter training }\end{array}$ & $\begin{array}{l}\text { Gardner }(1985) \\
\text { Yan et al. }(2010)\end{array}$ \\
Avoidance & $\begin{array}{l}\text { possible negative outcomes one tries to } \\
\text { avoid if one fails in interpreter training }\end{array}$ & $\begin{array}{l}\text { Higgins }(1987,1998) ; \\
\text { Dörnyei }(2009) \\
\text { Rosiers et al. (2011) }\end{array}$ \\
\hline
\end{tabular}

\section{Research design}

\subsection{Research questions}

The research is guided by the following research questions:

a) What is the motivation and demotivation profile of interpreter trainees?

b) How are the external and internal factors correlated with trainees' motivation and demotivation in interpreter training?

\subsection{Participants and procedures}

The participants involved in this study were purposely sampled from Guangdong University of Foreign Studies (GDUFS), a certified CIUTI (Conference Internationale Permanente d'Instituts Universitaires de 
Traducteurs et Interprètes) member institute. The university has a long tradition of running translation and interpreting programmes, dating back to the 1970s. It is believed that interpreter trainees at this university are generally highly motivated, since they have to survive intense competition for acceptance. The reason of deliberate sampling is to tap into a wider range of potential demotivating factors in interpreter training, because to study demotivating factors, "motivation must exist before there can be a subsequent decrease" (Falout, Elwood \& Hood, 2009).

As there is no existing questionnaire specifically addressing trainees' (de)motivation issues in interpreter training, an open-ended essay question was administered to 40 MTI (Master of Translation and Interpreting) trainees, who had been trained for about nine months. The essay prompt was "Please write a reflective essay about your experience of interpreter training in this semester". The text responses were collected and coded, using a grounded theory approach (Strauss \& Corbin, 1990). The qualitative findings of these essays will be presented in 5.1.

As a second step, demotivation items and demotivating factors were generalised from the qualitative findings and formed a part of the questionnaire. To be specific, the questionnaire had three dimensions and six constructs (see Table 2). The resultant questionnaire consisted of 36 selfreported items, and was designed to have 6-point Likert scale responses, with 1 meaning "totally disagree" and 6 "totally agree". Even-numbered responses were employed to avoid the possibility where respondents might choose the middle category, because Asians have a tendency to do so (Chen, Lee \& Stevenson, 1995).

Table 2. Number of items and sources of the constructs in the questionnaire

\begin{tabular}{|c|c|c|c|c|}
\hline Factors & & $\begin{array}{l}\text { \# of } \\
\text { Items }\end{array}$ & sources & $\begin{array}{l}\text { Cronbach's } \\
\text { alpha }\end{array}$ \\
\hline \multirow{3}{*}{ Criterion } & Motivation & 6 & $\begin{array}{l}\text { Developed from the definition (see } \\
\text { section 3) }\end{array}$ & .851 \\
\hline & & & & \\
\hline & Demotivation & 5 & $\begin{array}{l}\text { Developed from trainees' essay } \\
\text { responses }\end{array}$ & .808 \\
\hline \multirow{3}{*}{ Internal } & Ideal-self & 4 & Adapted from Dörnyei $(2010$, p. 140) & .795 \\
\hline & Avoidance & 3 & Adapted from Dörnyei (2010, p. 141) & .658 \\
\hline & Instrumentality & 2 & Adapted from Dörnyei $(2010$, p. 142) & .874 \\
\hline External & $\begin{array}{l}\text { Demotivating } \\
\text { Factors }\end{array}$ & 16 & $\begin{array}{l}\text { Developed from trainees' essay } \\
\text { responses and selected after expert } \\
\text { consultation }\end{array}$ & .713 \\
\hline
\end{tabular}

As a third step, questionnaires were administered to 120 interpreter trainees (see Table 3 for details) in the university. 70 of them were from the MTI programme and 50 were from the Bachelor of Translation and Interpreting (BTI) programme. At the time when the study was conducted, the MTI Group had had roughly four months of institutional training, and the BTI Group two years and a half. Participation was voluntary and anonymity and confidentiality were also ensured. It is noteworthy that there are no males in the BTI program, but this is quite normal in the university, because over the past five years it has had a maximum of three male trainees in a class. In addition, this study does not focus on or compare the demographic difference between genders. Therefore, if we had omitted the BTI group, we would not have been exposed to as many demotivators as we are now. 
Table 3. Demographic details of the participants involved

\begin{tabular}{lllllll}
\hline Group & Data type & $\begin{array}{l}\# \\
\text { trainees }\end{array}$ & & Male & Female & \multicolumn{2}{l}{ Age (years) } \\
\cline { 6 - 7 } & & & & & Mean & SD \\
\hline MTI & essays & 40 & 3 & 37 & 20.65 & 1.67 \\
MTI & questionnaires & 70 & 12 & 58 & 22.93 & 1.50 \\
$\mathbf{B T I}$ & questionnaires & 50 & 0 & 50 & 19.94 & 0.82 \\
\hline
\end{tabular}

\section{Results and Discussion}

\subsection{Qualitative findings}

As described above, 40 interpreter trainees were prompted to write a reflective essay about their interpreter training experience. As this study focuses on demotivating factors, coding was performed to highlight the sentences containing the causes leading to trainees' decreased motivation. For example, the following extract was singled out in the coding process:

I really want to practice more, but in [the Guangdong University of Foreign Studies], it could not even accommodate a place for us to practice interpreting (MTI-16)

After all the extracts were highlighted, similar expressions were merged and factors were generalised based on iterative readings. For instance, the above statement was generalised as a demotivating factor: "It is hard to find a place to practice interpreting in." When all the demotivating factors were identified, the author presented them to two experts (one in translation studies and the other in motivation studies) to confirm the plausibility of the items. This step yielded 16 demotivating factors, which are shown in Table 4, along with their reported frequency.

Table 4. Demotivating factors reported by trainees

\begin{tabular}{|c|c|c|c|}
\hline \multirow{2}{*}{$\begin{array}{l}\text { Demotivating factors } \\
\text { My grade in interpreting is inferior to my peers'. }\end{array}$} & \multicolumn{2}{|c|}{ Frequency (\%) } & \multirow{2}{*}{$\begin{array}{l}\text { Category } \\
\text { Self }\end{array}$} \\
\hline & 33 & $82.50 \%$ & \\
\hline My grade in interpreting is bad. & 31 & $77.50 \%$ & Self \\
\hline $\begin{array}{l}\text { It is hard to find appropriate materials to practice } \\
\text { interpreting. }\end{array}$ & 28 & $70.00 \%$ & Self \\
\hline $\begin{array}{l}\text { Interpreting teachers seldom demonstrate interpreting } \\
\text { skills in class. }\end{array}$ & 27 & $67.50 \%$ & Teacher \\
\hline It is hard to find a place to practice interpreting in. & 26 & $65.00 \%$ & Institute \\
\hline It is hard to find a partner to practice interpreting with. & 23 & $57.50 \%$ & Peer \\
\hline The materials used in interpreting lessons are difficult. & 22 & $55.00 \%$ & Teacher \\
\hline My peers are not that willing to practice interpreting. & 22 & $55.00 \%$ & Peer \\
\hline $\begin{array}{l}\text { It is hard to ask teachers for feedback when practicing } \\
\text { interpreting after class. }\end{array}$ & 20 & 50. & Teacher \\
\hline Interpreting teachers' explanation is not sufficient. & 18 & $45.00 \%$ & Teacher \\
\hline Interpreting lessons are boring. & 16 & $40.00 \%$ & Teacher \\
\hline Interpreting lessons are exam-oriented. & 12 & $30.00 \%$ & Teacher \\
\hline Interpreting teachers are strict. & 12 & $30.00 \%$ & Teacher \\
\hline $\begin{array}{l}\text { There are too many courses in one semester, making it } \\
\text { hard to focus on interpreting learning. }\end{array}$ & 9 & $22.50 \%$ & Institute \\
\hline $\begin{array}{l}\text { Interpreting teachers provide little information about the } \\
\text { interpreting market. }\end{array}$ & 7 & $17.50 \%$ & Teacher \\
\hline $\begin{array}{l}\text { The materials used in interpreting lessons are largely } \\
\text { decided by teachers, with few trainees' choices. }\end{array}$ & 4 & $10.00 \%$ & Teacher \\
\hline
\end{tabular}


These 16 items show that the demotivating factors are multi-dimensional, ranging from teaching methods to practice materials, from teachers to trainees themselves. When these items are categorized, it seems appropriate to group them on the basis of the attribution, i.e. where trainees assign/attribute their causes. Four actors were identified: trainees themselves, peers, teachers and the institute. According to the aggregated frequencies, teachers were the most frequently reported category $(44.51 \%)$, followed by the self-attribution category $(29.68 \%)$. This could be interpreted that teachers were deemed the most significant factor leading to trainees' demotivation. As reported by the trainees, the teaching materials, teaching methods, syllabus design, and teachers' behaviours were all potential demotivating factors. A similar pattern was also observed in other studies (Gorham \& Millette, 1997) and corroborated by the quantitative findings in this study, which are reported in 5.2.2.

In the questionnaire stage, all of the items in Table 4 were used. In order to understand the underlying structure among these reported items, principal component analysis (PCA) with Varimax rotation was performed, based on the responses from 120 trainees. Initially, six components were extracted, but in three of them, there was only one item, which warranted deletion (Field, 2009 , p. 641-642). After step-wise exclusion, finally, three components with an eigenvalue exceeding 1 were extracted, with a total of $57.18 \%$ variance explained. The three components could be labelled as Teaching Methods, Perceived Supports and Perceived Competence ${ }^{1}$. It is noted that these three components are slightly different from the four categories reported in Table 4; but it is believed that components extracted from the PCA are statistically more valid in uncovering the latent structures of items (ibid). Therefore, in the subsequent quantitative analysis, Teaching Methods, Perceived Supports and Perceived Competence will be adopted to represent the three external demotivating factors.

\subsection{Quantitative findings}

5.2.1 Motivation and demotivation profile of interpreter trainees: Descriptive statistics show that the motivation level of 120 trainees is generally high $(\mathrm{M}=4.02, \mathrm{SD}=1.07)$. This is expected, because, as mentioned in section 4.2, this study specifically focuses on the trainees with high aspiration in interpreter training. The demotivation level is moderate $(M=3.36$, $\mathrm{SD}=1.07)$. This seems to suggest that even though trainees are highly motivated in the interpreting programme, they are not immune to demotivation. An independent sample t-test shows that there is no statistical difference between the BTI and the MTI groups, either in the Motivation level $(\mathrm{t}=.851, \mathrm{df}=118, \mathrm{p}=.40>.05)$ or in the Demotivation level $(\mathrm{t}=.337, \mathrm{df}=118$, $\mathrm{p}=.737>.05)$. This means that interpreter trainees, whether in the BA or the MA level, share the similar intensity of (de)motivation. In other words, demotivation seems to be present across different training levels, and might pose as a potential and constant threat to trainees.

5.2.2 External and internal factors correlated with trainees' motivation and demotivation: To uncover the factors related to (de)motivation in interpreter training, a Spearman correlation analysis was performed in the

1. Due to space constraints, the factor loadings are not shown here. Interested readers may contact the author for details. The Teaching Methods Component includes Item 4, 7, 10, 11, 12; the Perceived Supports Component includes Item 3, 5, 6, 8; and the Perceived Competence Component includes Item 1 and 2. 
eight constructs surveyed in the questionnaire. As shown in Table 5, Motivation is negatively correlated with Demotivation $(r=-.628, \mathrm{p}<.001)$. This indicates that trainees with higher motivation are less likely to be demotivated in training. In addition, Motivation is found positively correlated with Ideal Self $(r=.554, p<.001)$, meaning that the more trainees incorporate interpreting with their ideal future-self, the more engaged they are in training. This corroborates with previous findings that "positive self-image acts as an important prerequisite for investing effort in language learning" (Kormos \& Csizér, 2014).

Table 5. Correlation matrix between eight constructs

\begin{tabular}{llllllll}
\hline Construct & $\mathbf{1}$ & $\mathbf{2}$ & $\mathbf{3}$ & $\mathbf{4}$ & $\mathbf{5}$ & $\mathbf{6}$ & $\mathbf{7}$ \\
\hline 1. Motivation & & & & & & & \\
2. Demotivation & $-.628^{* *}$ & & & & & & \\
3. Ideal Self & $.554^{* *}$ & $-.198^{*}$ & & & & & \\
4. Instrumentality & $.254^{* *}$ & -.129 & $.458^{* *}$ & & & & \\
5. Avoidance & -.158 & $.205^{*}$ & .072 & .174 & & & \\
6. Teaching Methods & $-.568^{* *}$ & $.358^{* *}$ & $-.208^{*}$ & .009 & $.312^{* *}$ & & \\
7. Perceived Supports & $-.292^{* *}$ & $.295^{* *}$ & .083 & $.212^{*}$ & $.224^{*}$ & $.378^{* *}$ & \\
8. Perceived Competence & $-.486^{* *}$ & $.265^{* *}$ & $-.341^{* *}$ & -.144 & $.271^{* *}$ & $.348^{* *}$ & $.270^{* *}$ \\
\hline${ }^{* *} p<.01{ }^{*} p<.05$ & & & & & & &
\end{tabular}

Another interesting finding is that Avoidance is positively correlated with Demotivation $(\mathrm{r}=.205, \mathrm{p}=.024<.05)$, but not with Motivation $(\mathrm{r}=-.158$, $\mathrm{p}=.085>.05)$. This indicates that if trainees are more apprehensive about failing their training, they would be more likely to be demotivated; but avoidance alone might not be a sufficient condition to trigger motivational behaviours in interpreter training.

As one of the three Demotivating Factors, Teaching Methods is found to be negatively correlated with Motivation $(\mathrm{r}=-.568, \mathrm{p}<.001)$ and positively with Demotivation $(\mathrm{r}=.358, \mathrm{p}<.001)$. The same pattern is also identified in Perceived Supports and Perceived Competence, where they are negatively correlated with Motivation $(\mathrm{r}=-.292, \mathrm{p}=.001 ; \mathrm{r}=-.486, \mathrm{p}<.001)$ and positively with Demotivation $(\mathrm{r}=.295, \mathrm{p}<.001 ; \mathrm{r}=.265, \mathrm{p}=.003)$.

To elaborate on the demotivating factors, two points are noteworthy. First, among the three Demotivating Factors, it seems that Teaching Methods have the largest impact on trainees' (de)motivation, evidenced by its largest correlation coefficients. This finding corroborates the results in the qualitative findings reported in 5.1 and also echoes the research in the broader settings of educational psychology, where researchers found that students usually "attributed more of their demotivation to teacher behaviour" and they "were significantly more critical of overall instructional process decisions related to delivery of course material" (Gorham \& Millette, 1997). It is also congruent with earlier research findings by Zhang (2007), Christophel and Gorham (1995) and Dörnyei (1998), where teachers' (mis)behaviours were regarded by students as a strong demotivating factor, or even the strongest one (Trang \& Baldauf, 2007).

Second, Perceived Competence stands out as a demotivating factor, because it might result in trainees' anxiety. Consistently failing or doing badly in interpreting tests would lead them to conclude that they are incapable of surmounting failure, or known as "learned helplessness" in educational psychology (Dweck, 1975). "This perception is associated with attributions of failure to uncontrollable, invariant factors such as lack of ability, rather than to controllable factors such as effort" (Diener \& Dweck, 1978). In other words, if trainees constantly experience failure in interpreter training, they would be less likely to sustain their efforts. 


\section{Implications}

In this section, theoretical and pedagogical implications are explored to highlight the importance and necessity of researching motivation of interpreter trainees and understanding their motivational beliefs and behaviours.

\subsection{Theoretical Implications}

When researched, motivation in interpreter training was treated as a static and monolithic variable. This exploratory study, however, sheds light on the complexity of (de)motivation. The complexity could be unpacked in three aspects: dynamic, situated and multifaceted (Schunk, Meece \& Pintrich, 2013). First, as suggested in this study, the motivation and demotivation levels of an interpreter trainee are not inversely proportionate to each other. That is, an interpreter trainee should not be dichotomously labelled as "motivated" or "not motivated" (Fan, 2012). The current study shows that even though interpreter trainees have a generally high level of motivation, they still experience a moderate level of demotivation. Interpreting teachers should be aware of the risk that highly motivated trainees are not entirely immune to demotivation over the course of training. Trainees might be simultaneously motivated and demotivated, which signifies the dynamic nature of motivation.

Second, trainees' motivation is situated in the teaching context. Trainees are responsive and adaptive to the external factors: in this case, peers, teachers and the training institute. Although the participants in this study generally had a high level of motivation, they reported a wide range of demotivators in their reflective essays, highlighting the potential demotivating effects of teachers and the institute. This study shows that teachers seem to be the most frequent demotivators to trainees, which means that trainees' (de)motivation is strongly sensitive to and inherently situated in teachers' behaviours. In light of this, interpreter trainers need to conduct periodic review on their instruction methods and engage in trainer-trainee dialogue to mitigate the demotivating effects on trainees.

Third, (de)motivators of interpreter trainees are multi-dimensional. Trainees are (de)motivated by a host of factors, the importance of which vary from one scenario to another. For example, this study shows that the top three motivators of trainees are trainers' Teaching Methods, trainees' Ideal Self and trainees' Perceived Competence, while trainers' Teaching Methods, trainees' Perceived Supports and Perceived Competence are the top three demotivators. Understanding the multidimensionality of (de)motivators will enable researchers to expand and reframe their research agenda. By far, motivation is understood as a volitional and emotional variable and is usually studied as the independent variable, predicting the trainees' interpreting performance (Shaw, 2011; Timarová \& Salaets, 2011; see Figure 1). This study suggests that motivation itself is multi-faceted. It entails the dynamic nature of motivation and demotivation. It needs to be studied as a dependent variable and an independent variable at the same time. As is shown in Figure 2, trainees' (de)motivation is understood as the dependent variable (determined by the factors on the part of trainees, peers, trainers and institutes) and the independent variable (impacting trainees' interpreting performance). In addition to this, trainees' interpreting performance might be bilaterally related to their (de)motivation, and trigger (de)motivators on the part of trainees, peers, trainers and institutes, which eventually impact trainees' (de)motivation. Dotted lines are particularly adopted to indicate that the relationships between the variables are un- or under-examined in the extant literature and warrant further research. 


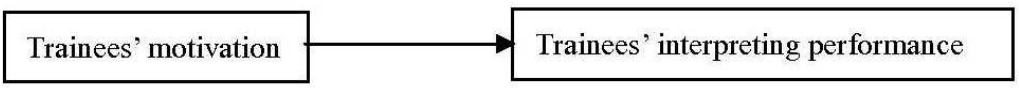

Figure 1: Motivation studied as an independent variable

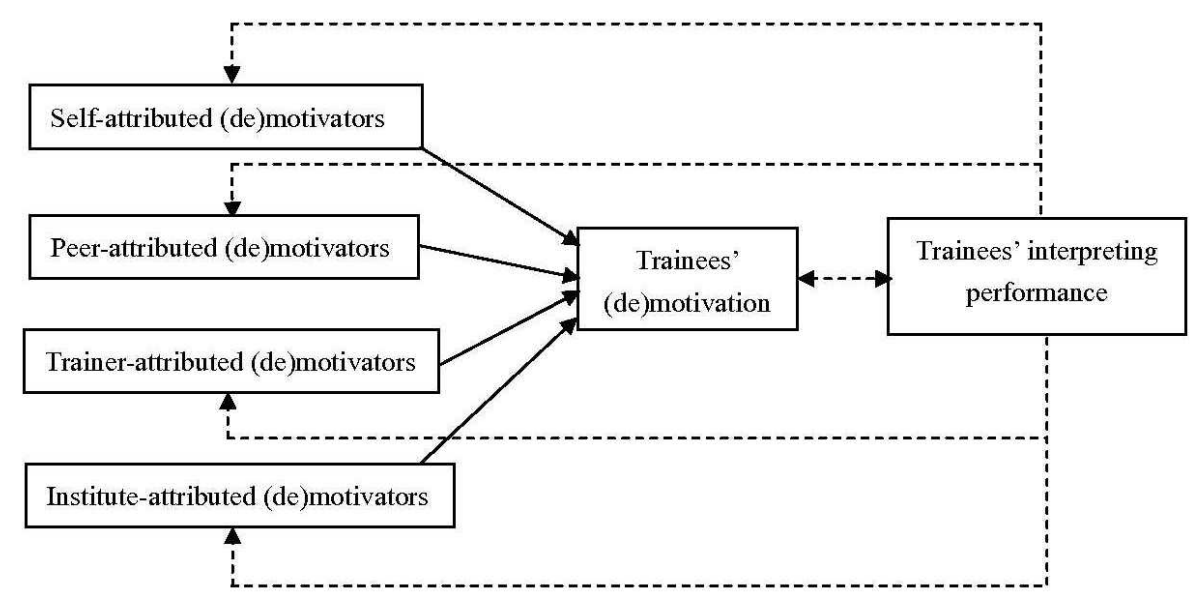

Figure 2: (De)motivation studied as a dependent and an independent variable

\subsection{Pedagogical implications}

Interpreter trainers in GDUFS are all practising conference interpreters, averaging 10 years of working experience in the interpreting market. One of them is an AIIC (International Association of Conference Interpreters) member. Despite this, the current study shows that teachers were the most frequently reported source of demotivators by the trainees. This seems to show that interpreting experience alone is not sufficient to make a satisfactory interpreter trainer. A close scrutiny of the demotivators in the teacher category (see Table 4) reveals that self-directed learning strategies are insufficient on the part of the trainees. That is, trainees are not well trained in managing and directing their learning, hence an overly high degree of reliance on the teachers' feedback (Wu, 2012), choice of materials and skill demonstration. Therefore, the first pedagogical implication of this study is to highlight the importance of learning strategies in interpreter training (Fan, 2012). Specifically, interpreting teachers need to train students to adopt 'strategy attribution' (Covington, 1998) in their training. Strategy attribution connects efforts and competence, and brings forth double benefits. If students adopt only the competence attribution in their training, they might conclude that they do not have the talent to be an interpreter (Sternberg, 2001) and give up training. On the other hand, if students adopt only the effort attribution, they might sustain their motivation for a while and commit themselves to deliberate practice (Ericsson, 2000); however, as they do not modify their learning strategies, they might not be able to achieve significant progress, eventually leading to demotivation. Strategy attribution is ideal for interpreter trainees, enabling them to realize that they need both self-directed learning strategies and deliberate practice to build their interpreting competence.

The second pedagogical implication is to recognize the limited effect of using utilitarian benefits to motivate interpreter trainees. In China, it has been suggested to drive trainees' motivation upward by focusing on the practical (especially monetary) benefits derived from interpreter training (Wang \& Duan, 2013, p. 160). This study, however, shows that emphasis on utilitarian 
gains is at best a quick-fix. What really sustains trainees' motivation is the Ideal Self: how much they want their future selves to be associated with interpreting. Therefore, trainers could organize some ideal-self activities in the interpreter training (for ideas of ideal-self activities, see Hadfield \& Dörnyei, 2013). Activities such as 'meeting your professional self in 10 years' could allow trainees to visualise a professional career and evoke a sense of professionalism, thereby fuelling their motivation and enthusiasm for training.

\section{Conclusion}

This exploratory study addresses the issues of trainee (de)motivation in interpreter training. After surveying 160 interpreter trainees in a highly acclaimed interpreter training institute in China, the study shows that: (1) undergraduate and postgraduate trainees, although generally high in motivation, are susceptible to demotivation; (2) trainees' Ideal Self (future-self guide) is a better motivator than Instrumentality and Avoidance; (3) factors leading to trainee demotivation could be categorized into four groups: self-, peer-, teacher-, and institute-attributed. Qualitative findings show that Teacher Factor is the most frequently cited demotivating factor.

Based on the previous findings, the author proposes that the research agenda concerning motivation in interpreting studies needs to be expanded. Instead of treating motivation as a monolithic independent variable, this study points out that motivation is dynamic, situated and multifaceted, and should be researched as both a dependent variable and an independent variable in interpreting studies. In addition, this study highlights the pedagogical importance of training interpreter trainees to adopt 'strategy attribution' and to incorporate their Ideal Self into interpreting training - two new measures for encouraging and sustaining trainee motivation.

\section{Acknowledgements}

The author would like to thank the anonymous reviewers for their constructive comments. This research was supported by the Innovative School Project in Higher Education of Guangdong, China (GWTP-LH-2015-02).

\section{References}

Angelelli, C. V. (2006). Designing curriculum for healthcare interpreting education: A principles approach. In C. B. Roy (Ed.), New approaches to interpreter education (pp. 23-46). Washington: Gallaudet University Press.

Bontempo, K., \& Napier, J. (2011). Evaluating emotional stability as a predictor of interpreter competence and aptitude for interpreting. Interpreting, 13(1), 85-105.

Chen, C., Lee, S.-Y., \& Stevenson, H. W. (1995). Response style and cross-cultural comparisons of rating scales among East Asian and North American students. Psychological Science, 6, 170-175.

Christophel, D., \& Gorham, J. (1995). A test-retest analysis of student motivation, teacher immediacy and perceived sources of motivation and demotivation in college classes. Communication Education, 44, 292-306.

Covington, M. V. (1998). The will to learn: A guide for motivating young people. Cambridge: Cambridge University Press.

Csizér, K., \& Kormos, J. (2009). Modelling the role of inter-cultural contact in the motivation of learning English as a foreign language. Applied Linguistics, 30, 166-185.

Diener, C. I., \& Dweck, C. S. (1978). An analysis of learned helplessness: Continuous 
changes in performance, strategy, and achievement cognitions following failure. Journal of Personality and Social Psychology, 36, 451-462.

Dweck, C. S. (1975). The role of expectations and attributions in the alleviation of learned helplessness. Journal of Personality and Social Psychology, 31, 674-685.

Dörnyei, Z. (1998). Motivation in second and foreign language learning. Language Teaching, 31, 117-135.

Dörnyei, Z. (2009). The L2 Motivational Self System. In Z. Dörnyei \& E. Ushioda (Eds), Motivation, language identity and the L2 self (pp. 9-42). Bristol: Multilingual Matters.

Dörnyei, Z. (2010). Questionnaires in second language research: Construction, administration, and processing (2nd ed.). London: Routledge.

Dörnyei, Z., \& Skehan, P. (2003). Individual differences in second language learning. In C. J. Doughty \& M. H. Long (Eds.), The handbook of second language acquisition (pp. 589-630). Oxford: Blackwell.

Dörnyei, Z., \& Ushioda, E. (2011). Teaching and researching motivation (2nd ed.). Harlow: Longman.

Ellis, R. (2001). The metaphorical constructions of second language learners. In M. P. Breen (Eds.), Learner contributions to language learning (pp. 65-85). Edinburgh: Pearson Education.

Ericsson K. A. 2000. Expertise in interpreting: An expert-performance perspective. Interpreting, 5(2), 189-222.

Falout, J., Elwood, J., \& Hood, M. (2009). Demotivation: Affective states and learning outcomes. System, 37(3), 403-417.

Fan, D. (2012). The development of expertise in interpreting through self-regulated learning from trainee interpreters. (Unpublished doctoral dissertation). Newcastle University, UK.

Field, A. (2009). Discovering statistics using SPSS ( $3^{\text {rd }}$ ed.). Thousand Oaks, CA: Sage publications.

Gardner, R. C. (1985). Social psychology and second language learning: The role of attitudes and motivation. London: Edward Arnold.

Gardner, R. C., \& Maclntyre, P. D. (1992). A student's contribution to second language learning: Part I. Cognitive factor. Language Teaching, 25, 211-220.

Gardner, R. C., \& MacIntyre, P. D. (1993). A student's contributions to second language learning Part II: Affective variables. Language Teaching, 26, 1-11.

Gilles, A. (2013). Conference interpreting: A student's practice book. Abingdon, New York: Routledge.

Gorham, J., \& Christophel, D. (1992). Students' perception of teacher behaviors as motivating and demotivating factors in college classes. Communication Quarterly, 40, 239-52.

Gorham, J., \& Millette, D. (1997). A comparative analysis of teacher and student perceptions of sources of motivation and demotivation in college classes. Communication Education, 46, 245-261.

Hadfield, J., \& Dörnyei, Z. (2013). Motivating learning. Harlow: Pearson.

Higgins, E. T. (1987). Self-discrepancy: A theory relating self and affect. Psychological Review, 94, 319-340.

Higgins, E. T. (1998). Promotion and prevention: Regulatory focus as a motivational principle. Advances in Experimental Social Psychology, 30, 1-46.

Kormos, J., \& Csizér, K. (2008). Age-related differences in the motivation of learning English as a foreign language: Attitudes, selves and motivated learning behaviour. Language Learning, 58, 327-355.

Kormos, J., \& Csizér, K. (2014). The interaction of motivation, self-regulatory strategies, and autonomous learning behavior in different learner groups. TESOL Quarterly, 48(2), 275-299.

Larsen-Freeman, D. 2001. Individual cognitive / affective learner contributions and differential success in second language acquisition. In M. P. Breen (Eds.), Learner contributions to language learning (pp. 12-24). Edinburgh: Pearson Education.

Rosiers, A., Eyckman J., \& Bauwens D. (2011). A story of attitudes and aptitudes? Investigating individual difference variables within the context of interpreting. Interpreting, 13(1), 53-69.

Schunk D. H., Meece J. R., \& Pintrich P. R. (2013). Motivation in education: Theory, 
research, and application (International Edition). London: Pearson Education.

Shaw, S. (2011). Cognitive and motivational contributors to aptitude: A study of spoken and signed language interpreter trainees. Interpreting, 13(1), 70-84.

Sternberg, R. J. (2001). Giftedness as developing expertise: A theory of the interface between high abilities and achieved excellence. High Ability Studies, 12(2), 159179.

Strauss, A., \& Corbin, J. M. (1990). Basics of qualitative research: Grounded theory procedures and techniques. Thousand Oaks, CA: Sage Publications, Inc.

Timarová, S., \& Salaets, H. (2011). Learning styles, motivation and cognitive flexibility in interpreter training: Self-selection and aptitude. Interpreting, 13(1), $31-52$.

Trang, T. J., \& Baldauf, R. (2007). Demotivation: Understanding resistance to English language learning - The case of Vietnamese students. The Journal of Asia TEFL, 4(11), 79-105.

Ushioda, E. (2014). Motivational perspectives on the self in SLA: A developmental view. In S. Mercer \& M. Williams (Eds.), Multiple perspectives on the self in SLA (pp. 127-141). Bristol: Multilingual Matters.

Wang, W., \& Duan, Y. (2013). Exploration on English majors' interpreting competence. Beijing: Foreign Language and Research Press.

$\mathrm{Wu}, \mathrm{Z}$. (2012). Towards a better assessment tool for undergraduate interpreting courses: A case study in Guangdong University of Foreign Studies and beyond. In Z. Tan \& G. Hu (Eds.), Translation and intercultural communication: Impacts and perspectives (pp. 240-265). Shanghai: Shanghai Foreign Language Education Press.

Wu, Z. (2015). Towards a motivational system of interpreting learning: An empirical study on five universities in South China. (Unpublished doctoral dissertation). Guangdong University of Foreign Studies, Guangzhou, China.

Yan, X., Pan J., \& Wang, H. (2010). Learner factors, self-perceived language ability and interpreting learning an investigation of Hong Kong tertiary interpreting classes. The Interpreter and Translator Trainer, 4(2), 173-196.

Zhang, Q. (2007). Teacher misbehaviors as learning demotivators in college classrooms: A cross-cultural investigation in China, Germany, Japan, and the United States. Communication Education, 56, 209-227. 